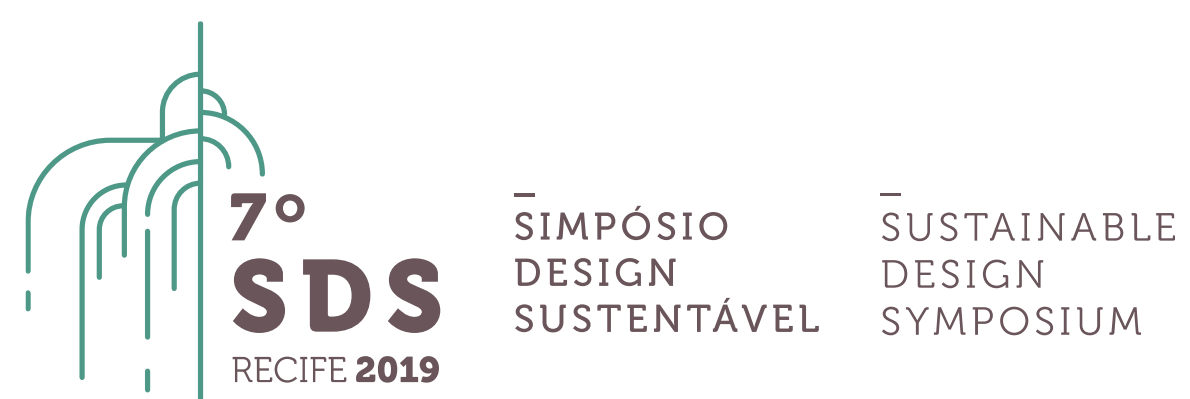

\title{
Modernização, progresso e desenvolvimento: desafios para o design na construção de perspectivas locais contra-hegemônicas
}

\author{
Sâmia Batista e Silva ${ }^{1}$, Washington Dias Lessa ${ }^{2}$ \\ ${ }^{1}$ Doutoranda, Universidade do Estado do Rio de Janeiro, \\ Programa de Pós-graduação em Design, sbatista@esdi.uerj.br \\ ${ }^{2}$ Doutor, Universidade do Estado do Rio de Janeiro, \\ Programa de Pós-graduação em Design, washington.lessa@gmail.com
}

\begin{abstract}
Resumo. Para compreender as perspectivas de desenvolvimento econômico e suas interfaces com o design, torna-se fundamental revisar as narrativas que conformam as políticas de desenvolvimento implementadas pelos governos nas iniciativas de modernização de territórios considerados atrasados, especialmente por meio de projetos de cooperação internacional. O presente artigo apresenta uma sucinta cronologia das teorias do desenvolvimento econômico, visando a compreensão de alinhamentos com a prática do design, abrangendo as medidas implementadas desde o processo de modernização no estabelecimento do capitalismo, até perspectivas atuais, que permitem a reflexão sobre o desenvolvimento a partir de uma ótica local, com a participação do design. A pesquisa bibliográfica foi o método utilizado para melhor compreender os discursos que definem as intervenções de designers junto a grupos vulnerabilizados social, territorial e economicamente.
\end{abstract}

Palavras-chave. Design, desenvolvimento, modernização, diversidade, decolonialismo.

Os interesses econômicos de cada momento colaboram para a construção de narrativas que influenciam, de forma marcante, as atividades e expressões humanas, dentre elas o design. Enquanto dispositivo fundamental do progresso técnico, o design se associa ao tema transversal deste artigo: a narrativa do desenvolvimento e seu avanço histórico. Suas raízes encontram-se na crença do progresso, propagada globalmente por meio de trocas comerciais compulsórias desde o período colonial, sendo utilizada para justificar o enquadramento de territórios diversos a uma lógica economicista ocidental, a despeito das conformações culturais e econômicas dos territórios subjugados. Nesse contexto, procura-se argumentar sobre como o design vem contribuindo para a reprodução de parâmetros de desenvolvimento desconectados das realidades locais, e, ao mesmo tempo, refletir sobre a participação do design em uma perspectiva pós- 
desenvolvimentista.

$\mathrm{Na}$ construção de respostas possíveis, faz-se necessário visitar os conceitos de desenvolvimento, modernização e diversidade, com base em Maluf (2000), Escobar (2005), Stavenhagen (1985), Léna (2012) e Mitschein (2018), que discorrem sobre os pressupostos do desenvolvimento econômico mundial, a teoria do desenvolvimento das décadas de 50 e 60; a teoria da dependência entre os anos 70 e 80 , e as noções do chamado pós-desenvolvimento, que ganharam evidência a partir da década de 90 . Os conceitos de etnodesenvolvimento, decrescimento e desenvolvimento local também são revisados. Já do campo do design surge a necessidade de refletir sobre relações entre design e desenvolvimento e sobre as recentes proposições decolonialistas em design, a partir da produção de Cardoso (2012), Margolin ${ }^{1}$ (2015) e Tunstall (2013).

\section{Desenvolvimento: do estatuto às crises}

"Desenvolvimento" significa mudança, evolução, crescimento, metamorfose. Mas devemos perguntar: desenvolvimento de onde para onde, e de quê para quê?; de pequeno a grande?; de atrasado a adiantado?; de simples a complexo?; de pobre a rico?; de inferior a superior?". (STAVENHAGEN, 1985, p.12)

Marcadas por controvérsias, as teorias que direcionaram as estratégias econômicas e políticas aplicadas pela maioria dos países desde o fim da Segunda Guerra seguem em processo de mutabilidade inexorável. As experiências associadas à corrente desenvolvimentista da década de 50 - cujo diagnóstico ilustrou o cenário de diferenças entre os países enriquecidos e empobrecidos pelos espectros colonial e imperialista geraram resultados de diversas qualidades. Para os países ricos a oportunidade de manter, reestabelecer e mesmo gerar processos de sujeição intelectual, financeira e cultural com os países pobres por meio de estratégias diversas, tais como as ações de cooperação internacional. Para os pobres, a importação de modelos de desenvolvimento estrangeiros sem considerar as especifidades locais, o endurecimento político justificado pela narrativa do nacionalismo e a reconfiguração da base produtiva visando a modernização da estrutura social e econômica por meio da industrialização. Na América Latina, assim como em outras ex-colônias, as tentativas frustradas de aproximação da realidade econômica dos países prósperos provocou a necessidade de revisões (Maluf, 2000).

A necessidade de repensar o desenvolvimento justifica-se, no mínimo, como contraposição à convencional prescrição de "mais crescimento econômico" acompanhado de instrumentos compensatórios das evidentes mazelas sociais e ambientais geradas pelos padrões de crescimento que vigoram até os dias atuais. (MALUF, 2000, p.55)

Uma das crenças associadas ao desenvolvimento na América Latina foi a de que a implantação de um sistema de base industrial seria capaz de superar a histórica vocação agrícola e, ao mesmo tempo, promover o crescimento econômico. Este, por sua vez, atenuaria as desigualdades sociais em função do efeito conhecido como "vazamento" do crescimento (Maluf, 2000, p.55), seja por meio da geração de emprego e renda, seja pela geração ou melhoria de infra-estruturas, além de outros elementos. Várias pesquisas, no entanto, confirmaram que o crescimento econômico não é suficiente para enfrentar a desigualdade e a pobreza, como em Maluf (2000): "(...) quanto maior a desigualdade

\footnotetext{
${ }^{1}$ MARGOLIN, Victor. Design for development: towards a history. Design Studies, v.28, n.2, mar. 2007: o artigo original foi traduzido para o português em 2015.
} 
inicial, menores os ganhos para os pobres com o crescimento econômico; mostram, também, que a redução da pobreza absoluta depende da distribuição da renda manter-se ao menos constante" (Maluf, 2000, p.56). Tal quadro não se alterou nas décadas seguintes, e os patamares relativos à incidência média da pobreza entre as décadas de 70 e 90 seguiram elevados, alcançando quase $50 \%$ da população, com uma redução inexpressiva da pobreza rural. A despeito do progresso técnico planejado pelas estratégias de industrialização na América Latina, a planejada modernização alcançou alguma efetividade apenas no plano do consumo, e não no plano da produção, sendo portanto ineficaz na redução das desigualdades, e, ao contrário, agravando-as.

A par dessa realidade, emergiu então a percepção de que os esforços dos países subdesenvolvidos não eram suficientes para tirá-los do quadro de atraso. Essa constatação deu origem posteriormente à teoria da dependência, que definiu a causa relacional do subdesenvolvimento. A teoria alcançou a esfera pública e virou tema de debates internacionais, servindo não apenas para a elaboração de estratégias de mitigação da exploração histórica (ainda que não assumida por muitas nações desenvolvidas) como também para justificar estratégias que reproduziram a lógica de exclusão social através do fortalecimento das burguesias locais (Stavenhagen, 1985).

A rejeição aos modelos desenvolvimentistas de origem estrangeira levou então à busca de alternativas por parte de governos dos países do chamado Terceiro Mundo, movimentos sociais e organizações diversas, dando origem a abordagens alternativas de desenvolvimento, já na década de 80 . Vislumbravam a priorização das necessidades básicas da população, no lugar de alcançar o padrão de consumo dos países ricos e taxas semelhantes de crescimento econômico. Outro ponto crucial seria o de entender o desenvolvimento a partir de visões endógenas, respondendo primeiramente às necessidades internas do que as demandas internacionais, passando por cima da divisão internacional do trabalho. As tradições culturais, uso de recursos locais, o uso equilibrado dos sistemas naturais e os sistemas politicamente participativos foram parâmetros também indicados pelas visões alternativas do desenvolvimento que manifestaram-se naquele momento histórico.

Ainda que essas hipóteses tenham ganhado importância na década de 80 , a supremacia do Estado Nacional também era um forte argumento para o desenvolvimento do país, levantando questões étnicas importantes. A diversidade precisava ser incluída nas discussões sobre o desenvolvimento. Diante desse cenário, Stavenhagen (1985) propõe a abordagem do etnodesenvolvimento, visando em linhas gerais a equalização de múltiplas injustiças, especialmente em um momento em que o controle de recursos naturais e o equilíbrio ecológico eram as principais pautas de discussão global. "Os planejadores e políticos de todo o mundo tem que lidar com fatores étnicos no desenvolvimento. No entanto, muitos deles preferem ignorar o assunto, porque ele pode questionar as premissas do estado-nação" (Stavenhagen, 1985: p.40). "O etnodesenvolvimento é concebido como um processo dinâmico e criativo que, mais do que limitá-las, pode liberar energias coletivas para o seu desenvolvimento" (id, p.43).

Nesse contexto, assistimos o florescer de diversas teorias alternativas e movimentos de resistência que confrontam o caráter de dominação dos processos de modernização das nações entendidas como atrasadas. É o caso das teorias que ajudam a pensar um estado de pós-desenvolvimento, propostas que surgiram no contexto de produção do conhecimento da década de 90 , em um cenário de novas tendências e campos em consolidação desde a década de 80 , tais como o pós-estruturalismo, os estudos culturais, a teoria feminista e o estudos étnicos e do meio ambiente, do qual participam as reflexões de Stavenhagen. 
As críticas à modernidade ${ }^{2}$ evidenciam os efeitos problemáticos associados ao discurso histórico do desenvolvimento, sustentado por um aparato institucional que garantiu sua inserção bem sucedida no âmbito das ideias e das práticas sociais dos países do terceiro mundo. A retórica do desenvolvimento foi fortalecida igualmente por meio da sua instituição e pelo surgimento de conhecimentos especializados, cujos detentores seriam os países do primeiro mundo, que passaram a exportar expertise aos países dependentes.

A valorização dos conhecimentos dos países desenvolvidos consolidou formas diversas de exclusão, desqualificando o conhecimento dos povos nativos, da era précolonial. Para os teóricos do pós-desenvolvimento tais sintomas revelam a urgência do abandono do conceito do desenvolvimento como organizador central da vida social, abrindo espaço para as culturas locais e seus conhecimentos adquiridos na relação com seus territórios (Escobar, 2005, p.20). Essa concepção crítica se ocupa da criação de outros discursos e representações, dissociados da concepção de desenvolvimento, valorizando práticas e saberes de sujeitos e agentes que foram silenciados pelo processo de modernização. Para isso, destacam as adaptações, subversões, resistências e estratégias alternativas efetuadas por esses atores em intervenções voltadas ao desenvolvimento, atribuindo-lhe um novo significado. Escobar sintetiza sua reflexão pontuando a importância do momento atual, condicionando a nossa capacidade de compreensão sobre a realidade, derivada do processo de modernização, à possibilidade do pós-desenvolvimento vir a ser um imaginário socialmente efetivo. Diagnostica que vivemos um momento de transição, em direção à uma realidade ainda não definida, mas cuja percepção dos efeitos da modernidade vem se estabelecendo.

Do conjunto de críticas ao desenvolvimento participam também as teorias que defendem o decrescimento, que priorizam a análise dos efeitos da modernidade sobre 0 meio ambiente, diante da ampla documentação científica desenvolvida sobre o assunto. $O$ vínculo entre o consumo de recursos naturais e a ilimitada necessidade de crescimento econômico revelaram seus limites e suas conexões com as repetidas crises sociais, econômicas e ecológicas. Para contrapor as evidências científicas alarmantes, as grandes corporações investem em pesquisas que relativizam os dados sobre as crises ambientais, bem como participam de lobbies políticos e midiáticos para influenciar a opinião pública a questionar a seriedade dos estudos científicos.

Léna (2012) efetua um panorama das críticas ao desenvolvimento, com foco na análise do chamado "Desenvolvimento Sustentável", caracterizado mais como uma adaptação às demandas ambientais sem, no entanto, questionar os seus estatutos, tais como o crescimento econômico, o consumismo e os mecanismos que reproduzem as desigualdades. "A noção de desenvolvimento sustentável levantou muitas esperanças no campo socioambiental (e até ajudou a estruturar esse campo) porque oferecia um significante sintético conveniente para muitas aspirações que careciam de formulação operacional" (2012, p.33). A teoria do decrescimento, e seus múltiplos pressupostos, tem como crítica a falta de um corpus teórico estruturado, que possibilite apontar para perspectivas macroeconômicas que definam as bases da transição para uma economia que confronte a "mitologia do progresso" e a fé no crescimento econômico, sem gerar crises sociais mais graves do que as crises em processo (Léna, 2012, p.32-35). Diante de tal panorama, apresentamos a confuência entre o design e o desenvolvimento.

\footnotetext{
${ }^{2}$ Colocando o progresso como um "fetiche modernista" já superado, Cardoso (2012, p.31) apresenta três fenômenos que constituem o que ele chama de "espinha dorsal daquilo que chamamos de 'modernidade", quais sejam: a consolidação de grandes metrópoles, o surgimento de redes de transportes e comunicações e a difusão da comunicação visual impressa. Esses episódios foram sustentados pela expressiva industrialização, a consistência dos Estados nacionais e suas práticas mercantilistas e o crescente desenvolvimento científico e linguístico.
} 


\title{
2. Narrativas do desenvolvimento e a relação com design
}

Para entender a participação do design nas operações associadas ao desenvolvimento também é necessário efetuar uma pequena retrospectiva. Embora esse campo não seja evidenciado nas teorias já revisadas aqui, sua inserção nos processos e projetos de desenvolvimento remonta à década de 60. Margolin (2015) relata que as críticas ao desenvolvimento fomentaram o debate sobre a atuação dos designers nas conjunturas de desigualdade social. De um lado, sob a influência de Victor Papanek, uma visão crítica às consequências do industrialismo e do consumo. De outro, a leitura conciliadora de Gui Bonsiepe a partir da Declaração de Ahmedabad ${ }^{3}$, que resultou na proposição de um modelo polifásico de atuação do designer.

Em suas análises, Margolin demonstra otimismo em relação às políticas de cooperação - empreendidas para a redução das condições de miséria dos países pobres, com participação de designers na criação de soluções para o enfrentamento de tais condições -, e entende que o design é mal interpretado pelos governos e agências de financiamento, devido à sua baixa difusão. "As oportunidades para uma participação do design no processo de desenvolvimento são geralmente determinadas pela estrutura disponível de assistência ao desenvolvimento" (2015, p.25). Em contraposição, aponta o design como diferencial estratégico para tais políticas, em função da visão holística dos designers.

Embora não discuta profundamente as relações assimétricas entre os países, Margolin aponta a falta de interesse em incentivar a contratação de designers nos países receptores das políticas de assistência: "as empresas não se sentem incentivadas a trabalhar com designers que podem não ter níveis de sofisticação e conhecimento técnico iguais aos de profissionais advindos de países desenvolvidos" (id, p.26). Nesse caso, a valorização irrestrita do expertise estrangeiro em prejuízo do expertise local acaba por definir o design como um modelo universal a ser prescrito sem questionamentos. Há, porém, situações pelas quais os países dependentes acabam superando comercialmente os países que Ihes transferem tecnologia, como foi o caso do Japão e da Coréia no mercado de eletro-eletrônicos e automóveis, ultrapassando as vendas dos Estados Unidos. "(...) se o design começar a contribuir para o sucesso das grandes empresas nacionais, isso pode alterar ainda mais a assimetria das vantagens comerciais dos países desenvolvidos" (p.26). Margolin deixa de tecer críticas aos mecanismos de dependência exercidos pelos países desenvolvidos na consolidação das relações de poder globais. Por outro lado, considera o papel estratégico do designer na configuração de ambientes economicamente viáveis.

\begin{abstract}
Em primeiro lugar, a teoria do desenvolvimento deveria integrar melhor os múltiplos fatores que envolvem comércio, transferência de tecnologia e expansão cultural, e que afetam as condições de desenvolvimento. Enquanto os mecanismos de alívio de dívidas e os milhões de dólares que os países desenvolvidos e os organismos internacionais dedicam à erradicação da pobreza são essenciais, o que é mais necessário para o desenvolvimento é o fortalecimento das economias nacionais das nações em desenvolvimento, a fim de ajudá-las a melhor competir nos mercados globais (...). (MARGOLIN, 2015, p.26)
\end{abstract}

\footnotetext{
${ }^{3}$ A Declaração de Ahmedabad sobre design industrial e desenvolvimento (1979) foi o resultado das discussões sobre a promoção do design industrial em países em desenvolvimento, decorrentes da Conferência de Ahmedabad, organizada pelo Instituto Nacional de Design da Índia. Na ocasião, a Organização das Nações Unidas para o Desenvolvimento Industrial (UNIDO) e o Conselho Internacional de Sociedades de Design Industrial (ICSID) assinaram um protocolo visando a valorização do design nas iniciativas de desenvolvimento dos países periféricos.
} 
Diferente da visão de Margolin, a perspectiva decolonial do design confronta o discurso hegemônico relativo aos sentidos de inovação, desenvolvimento e progresso. $\mathrm{O}$ pensamento decolonial que emergiu de forma expressiva a partir da metade do século XX vem influenciando esse campo e posicionando autores no Brasil, China, África do Sul e outras ex-colônias, como a Austrália. Desses dois últimos partem as principais críticas acadêmicas ao design "colonizado" - entendido aqui como o design que reproduz os valores ocidentais capitalistas e pouco considera as subjetividades dos povos nãoocidentais.

No âmbito não-acadêmico, diversos profissionais que atuam junto a comunidades que subsistem da produção artesanal produzem duras críticas à oposição estabelecida entre o "design moderno" e o "design artesanal", pois exclui os processos de inovação vivenciados historicamente por essas comunidades. A partir desse contraste, a inovação em design é colocada como ferramenta de adequação à lógica do mercado, que responde à estética reprodutiva de valores modernistas, estabelecendo uma linha evolutiva de qualidade. $\mathrm{O}$ artesanato estaria, portanto, classificado como uma manifestação do atraso, enquanto a produção industrial projetada e reproduzida em série representaria o progresso.

Foi do pensamento linear ocidental que emergiu a tradição de classificar e hierarquizar tipos humanos - e a sua produção material -, estabelecendo as bases da Antropologia enquanto ciência. Sob prisma do sistema ocidental do conhecimento, tal processo contribuiu para a objetificação dos tipos não-ocidentais, subjugando suas visões autóctones sobre seus territórios. É na desconstrução dessa herança histórica que Tunstall (2013) aproxima sua crítica à tradição antropológica da crítica às metodologias de inovação em design, afirmando que o design hegemônico persiste na promoção de valores modernistas. Uma antropologia descolonizada seria então o fundamento para formas autônomas de atuação também no design, confrontando a tendência imperialista atribuída às metodologias de projeto originadas nos países "desenvolvidos" e aplicadas nos países "em desenvolvimento". Historicamente, iniciativas dessa natureza vem sendo reproduzidas sob formas de transferência tecnológica e de design, hierarquizando em termos de qualidade o design produzido nos países hegemônicos em relação aos nãohegemônicos.

Em oposição, a priorização das perspectivas locais vem sendo colocada como bandeira para a criação de alternativas à visão ocidental do desenvolvimento, inserindo o design nesse contexto. Na proposta metodológica apresentada por Tunstall, o Design Anthropology, o respeito aos sistemas de valores locais embasam as práticas híbridas de designers.

A antropologia do design, como eu a defino, vem diretamente de minhas experiências de ser uma mulher afro-americana que foi treinada em antropologia crítica e aplicada esse conhecimento aos contextos de design profissional e educação em design. Ele fala ao coração das atrocidades do colonialismo e imperialismo ocidentais, principalmente o desrespeito e desconsideração pelas experiências de outras pessoas. A antropologia do design encena a crítica da posicionalidade e do poder articuladas pelos estudiosos do Terceiro Mundo, estudiosos indígenas e feministas da segunda e terceira onda, reformulando as áreas problemáticas do impacto social como dentro dos sistemas de valores do imperialismo. (TUNSTALL, 2013, p.415, tradução nossa)

Os princípios dessa prática projetual pregam, em linhas gerais, pela aceitação do dinamismo da cultura; a eliminação da desigualdade nos processos de troca cultural; a clareza nos processos de transformação cultural; a igual valorização das práticas humanas que tornam tangíveis os sistemas de valores, como a arte, o artesanato e o 
design; que os processos interacionais entre designers e demais participantes do projeto sejam democráticos, inclusivos e reconhecidos e que, principalmente, os projetos promovam o questionamento dos valores hegemônicos que prejudicam grupos vulnerabilizados. Nesse cenário, a autora aponta para a necessidade premente de considerar as visões dos grupos que são vistos como objetos das iniciativas de inovação em design, aprofundando a noção da pesquisa etnográfica da prática projetual do design na busca de soluções.

\section{Considerações finais}

O convite para repensar o desenvolvimento ecoa de todos os lados. As propostas também são inúmeras, mas é imprescindível que sejam consideradas de acordo com as especificidades locais. A perspectiva local não pode, no entanto, ser vista como algo fechado à influências externas, dado ao dinamismo das trocas culturais e a diversidade implícita nessas trocas. Maluf $(2000$, p.75) considera fundamental "valorizar a diversidade em seu significado qualitativo na formulação de estratégias de desenvolvimento" e destaca quatro fatores de diversidade nesse sentido: cultural, institucional, humana e natural. Priorizado nos processos de desenvolvimento, o sentido quantitativo é representando, por exemplo, por fatores associados à superação da pobreza por pessoas ou países. Para o autor, repensar o desenvolvimento a partir de sua dimensão cultural permite "qualificar a suposta homogeneização decorrente de interpretações lineares do fenômeno da globalização, desvelar as formas de hegemonia cultural e rejeitar os padrões estandartizados de desenvolvimento econômico" (Maluf, 2000, p.78).

Em concordância com Maluf, Mitschein (2018, p.89) recomenda considerar "uma perspectiva de desenvolvimento que valorizasse a diversidade dos meios naturais e culturais das comunidades envolvidas". No Brasil, a maior dificuldade na proposição de visões alternativas ao desenvolvimento assenta-se sobre as disputas por territórios entre entidades governamentais e populações tradicionais, provocando o deslocamento de povos nativos ou provenientes dos processos de ocupação produtiva rural para a construção de infra-estruturas energéticas, extrativas e fabris - sendo ainda uma consequência da "ilusão desenvolvimentista" (Maluf, 2000, p.58) instaurada desde a ditadura. Cabe à todos descobrir novas formas para lidar com esse e outros desafios como a manutenção do sistema político vigente no país e a falta de articulação com os países vizinhos.

A desconstrução de padrões que ignoram a diversidade de mundos também é considerada por Stavenhagen: "Não existe nenhum processo evolutivo unilinear inequívoco que conduza da existência de uma multiplicidade de grupos étnicos a uma única cultura mundial, assim como não existe evolução unilinear de uma sociedade subdesenvolvida a uma desenvolvida" (Stavenhagen, 1985, p.41). A construção de novas perspectivas sobre o desenvolvimento também é contemplada pelos teóricos do decrescimento: (...) o decrescimento não é o contrário do crescimento, mas sim uma profunda mudança de valores que alguns chamam de mudança de civilização (Lena, 2012, p.33). Já Escobar nos convida para imaginar um mundo "depois do desenvolvimento" e "depois do Terceiro Mundo", a fim de superarmos a narrativa do desenvolvimento: "isso implicaria, como já observamos, a capacidade de imaginar algo além da modernidade e regimes econômicos, a guerra, o colonialismo, a exploração da natureza e das pessoas e do fascismo social que a modernidade trouxe em sua encarnação imperial global (Escobar, 2005, p.30, tradução nossa).

E é desde a modernidade, intrinsecamente ao processo de industrialização, que o design vem participando como recurso ativo na tangibilização dos valores hegemônicos dos países do $1^{\circ}$ mundo. Ao participar da exploração dos territórios até os seus limites 
sociais e ambientais, diversas narrativas contra-hegemônicas vem surgindo - como as relatadas neste artigo - e também influenciam o design.

Embora de forma ainda inicial, esse exercício comparativo permitiu constatar que as perspectivas apresentadas apontam para a quebra gradual do paradigma econômico capitalista, em direção à construção de formas autônomas de desenvolvimento econômico e social. Cabe aos designers resistirem criticamente ao discurso do desenvolvimento. Para confrontá-lo, é preciso questionar a narrativa do desenvolvimento enquanto centralidade, na proposição de novos cenários. A proposição de imaginários é tarefa corriqueira em projetos de design. Construí-las a partir das especificidades locais permite visualizar outros caminhos, outras formas de instituição de ideias e práticas e, portanto, de outras narrativas.

\begin{abstract}
A inovação em design e a antropologia têm muito a contribuir para combater a desigualdade global, mas devem primeiro adotar princípios claros de compromisso respeitoso com os valores das pessoas, a tradução deles através de processos de codesign inclusivo e a avaliação de seus efeitos nas experiências das pessoas a partir da perspectiva dos mais vulneráveis (TUNSTALL, 2013, p.416, tradução nossa).
\end{abstract}

No âmbito do design, portanto, chamamos a atenção para a necessidade de refletir sobre a reprodução de discursos hegemônicos originados na confluência das lógicas modernista e do desenvolvimento - berço do design -, bem como sobre o conceito de inovação em design, especialmente em projetos com grupos vulnerabilizados social, territorial e economicamente. O papel de mediação atribuído aos designers demanda a realização de alinhamentos contextuais, sendo que, em muitos casos, a assimetria entre as visões dos grupos atendidos e as instituições governamentais ou empresariais que implementam os projetos conduz tais experiências ao fracasso, gerando frustração em ambas as partes. Tais dissonâncias refletem assim o choque cultural estabelecido pelas práticas ocidentais de design ao serem reproduzidas em realidades, formas de pensamento e visões distintas sobre a noção de desenvolvimento. Concordamos com Cardoso (2012, p.16), quando afirma:

Talvez a principal lição para o design - plenamente recebida e assimilada na prática dos designers brasileiros nos últimos vinte anos - seja a de que não existem receitas formais capazes de equacionar os desafios da atualidade. Não são determinados esquemas de cores e fontes, proporções e diagramas, e muito menos encantações como "a forma segue a função", que resolverão os imensos desafios do mundo complexo em que estamos inseridos. Seria cômico sugerir, ao projetar um eletrodoméstico, que despojá-lo de ornamento é mais importante do que minimizar seu impacto ambiental. Seria cruel, quase obsceno, propor que arejar a mancha de texto de uma página é uma boa maneira de tornar a leitura mais acessível, num país onde não se lê por opção e falta de opção. Parecem caricaturas maldosas, exageradas a ponto de se tornarem irrelevantes, mas estas são afirmações não muito distantes de um raciocínio que ainda prevalece em muitas faculdades de design. (CARDOSO, 2012, p.16).

A reinvenção de tais práticas, e de suas narrativas correlatas, se coloca como passo fundamental para a superação das limitações que foram - e continuam sendo -, impostas pelos interesses estrangeiros desde o projeto expansionista. É também um passo fundamental em direção ao estabelecimento de práticas de inovação de design autônomas. É esse exercício que vem colocando à prova o estatuto do design enquanto fenômeno ocidental moderno. A perspectiva ocidental o coloca como fruto do processo industrial europeu, mas as abordagens contemporâneas nos conduzem à reflexão sobre esse estatuto. Mais do que propor processos de inovação por meio do design, é preciso discutir os seus pressupostos enquanto saber e habilidade humana, a fim de desconstruir 
relações de poder instituídas historicamente.

\section{Referências}

CARDOSO, Rafael. Design para um Mundo Complexo. São Paulo: Cosac Naify, 2012.

ESCOBAR, A. El "postdesarrollo" como concepto y práctica social. In: Daniel Mato (coord.), Políticas de economía, ambiente y sociedad en tiempos de globalización. Caracas, Facultad de Ciencias Económicas y Sociales, Universidad Central de Venezuela, p. 17-31, 2005.

LÉNA, P. Os limites do crescimento econômico e a busca pela sustentabilidade: uma introdução ao debate. In: Léna, P. e Nascimento, E.P. (orgs.), Enfrentando os limites do crescimento - sustentabilidade, decrescimento e prosperidade. R. Janeiro, Garamond, 2012.

MALUF, R. S. Atribuindo sentido(s) ao desenvolvimento econômico. Estudos Sociedade e Agricultura, 15, 53-86, 2000.

MARGOLIN, Victor. Design para o desenvolvimento: mapeamento do contexto. In: PATROCÍNIO, Gabriel; NUNES, José Mauro (org). Design \& Desenvolvimento: 40 Anos Depois. São Paulo: Blucher, 2015.

MITSCHEIN, A. Thomas. Os povos colonizados, a via não capitalista ao desenvolvimento industrial e o legado de Franz Fanon para o hemisfério sul. Belém: IEMCI/UFPA, 2018.

STAVENHAGEN, Rodolfo. Etnodesenvolvimento: uma dimensão ignorada no pensamento desenvolvimentista. Anuário Antropológico, 84, p. 11-44, 1985.

TUNSTALL, Elizabeth. Decolonizing Design Innovation: Design Anthropology, Critical Anthropology, and Indigenous Knowledge In: Gunn W, Otto T, Smith RC, eds. 2013. Design Anthropology: Theory and Practice. London: Bloomsbury. p. 393-425. 